\title{
Surfactant Metabolism during Hyperventilation of Newborn Lambs with Atrial Right to Left Shunts
}

\author{
EVELYN D. RIDER, ALAN H. JOBE, TAKAKO YAMADA, MACHIKO IKEGAMI, \\ STEVE SEIDNER, AND LYNDA RUFFINI \\ Perinatal Research Laboratories, Department of Pediatrics, Harbor-UCLA Medical Center, UCLA School of \\ Medicine
}

\begin{abstract}
We studied the effect on surfactant metabolism of $8 \mathrm{~h}$ of mechanical ventilation at tidal volumes of $13 \pm 0.3 \mathrm{ml} / \mathrm{kg}$ and very high tidal volumes of $28 \pm 1.5$ $\mathrm{ml} / \mathrm{kg}$, with and without added $\mathrm{CO}_{2}$, in the presence of an atrial right to left shunt in 4- to 8-day-old lambs. Similarly aged, spontaneously breathing lambs were used as controls. Right to left atrial shunts were created by inflating a balloon in the right atrium after a Rashkind atrial septostomy, thus creating a stable, easily controlled atrial shunt. Radiolabeled surfactant phospholipid precursors were used to probe incorporation into and secretion of surfactant phosphatidylcholine, whereas intratracheally administered labeled natural surfactant was used to evaluate alveolar clearance. Protein leak from the vascular space to the lungs was measured using radioactive iodine-labeled albumins. At the end of the 8-h study period, tissue association of alveolar surfactant was significantly increased to $63 \%$ in the mechanically hyperventilated lambs as compared to $44 \%$ in those lambs mechanically ventilated but not hyperventilated $(p<0.05)$ and to $39 \%$ in the spontaneously breathing control animals $(p<0.05)$. No increased surfactant secretion or decreased compliance was detected with hyperventilation. However, the lambs had very large surfactant-saturated phosphatidylcholine pool sizes, and a large portion $(50 \%)$ was already in the alveolar pool, even in the spontaneously breathing lambs. Precursor incorporation into saturated phosphatidylcholine was similar in all groups, and very low and comparable protein leaks were seen in the different groups of lambs. These experiments did not detect any adverse effects of $8 \mathrm{~h}$ of mechanical ventilation, large atrial shunts or mechanical hyperventilation on the surfactant system of newborn lambs. (Pediatr Res 25:83-88, 1989)
\end{abstract}

In neonates with persistent pulmonary hypertension, hyperventilation has been considered an essential part of the ventilatory support (1). Suprasystemic pulmonary arterial pressures cause right to left shunts at the patent foramen ovale and ductus arteriosus levels which result in progressive hypoxemia. The goal of hyperventilation is to attain a critically low $\mathrm{PaCO}_{2}$ and alkaline $\mathrm{pH}$ which may promote reversal of the right to left shunt by decreasing pulmonary artery pressures to less than systemic levels (1). However, infants often become less responsive to the same

Received July 19, 1988; accepted September 13, 1988.

Correspondence Evelyn D. Rider, Department of Pediatrics, Bldg. A-17 Annex, Harbor-UCLA Medical Center, 1000 W. Carson St., Torrance, CA 90509.

Supported by Grant HD-12714 from the Department of Health and Human Services. degree of hyperventilation after 48-72 h, requiring higher peak inspiratory pressures to maintain the same level of oxygenation. At this stage, ventilator-induced pulmonary parenchymal disease and oxygen toxicity are other major factors causing hypoxemia rather than the right to left shunting (2). It is also possible that this subsequent respiratory deterioration is in part due to damage to the surfactant system by pulmonary edema fluid (3), damage to type II cells, alterations in surfactant metabolism (4), or effects of mechanical ventilation on surfactant (5).

Previous studies in isolated rat and dog lungs showed decreased compliance and increased minimum surface tensions with increased duration of ventilation at large tidal volumes for periods of up to $4 \mathrm{~h}(6,7)$. Oyarzun and Clements $(8,9)$ measured alveolar surfactant phospholipids in hyperventilated adult rabbits and found that alveolar surfactant increased during the first $2 \mathrm{~h}$ but substantially decreased after $4 \mathrm{~h}$ of increased tidal volume ventilation. They speculated that secretion was stimulated by hyperventilation, thereby increasing alveolar surfactant pools at the expense of tissue pools $(8,9)$. Similar conclusions were drawn by Wyszogrodski et al. from their study of hyperventilated adult cats (10). Morphometric analysis of hyperventilated and hypoperfused adult dog lungs showed decreased lamellar body volume densities in type II cells (11), and addition of $\mathrm{CO}_{2}$ to the inspired gases was found to moderate this effect (12).

Because differences between adult and newborn surfactant physiology exist (13), perhaps developmental differences in the response to mechanical ventilation at different tidal volumes would also occur. Using newborn lambs, we asked if surfactant phospholipid metabolism is altered by either mechanical ventilation or mechanical hyperventilation in the presence of an atrial right to left shunt with and without normalization of arterial $\mathrm{PCO}_{2}$ when compared to spontaneously breathing controls.

\section{MATERIALS AND METHODS}

Preparation of lambs. Healthy lambs 4 to 8 days of age were studied as four groups of five lambs each. Groups were ventilated as follows: group I: mechanically hyperventilated to $\mathrm{PaCO}_{2}$ of $15-20 \mathrm{~mm} \mathrm{Hg}$, tidal volume $25-40 \mathrm{ml} / \mathrm{kg}$; group II: mechanically hyperventilated to a similar level as group I except $\mathrm{CO}_{2}$ was added to the inspired gases to maintain $\mathrm{PaCO}_{2}$ at $35-45 \mathrm{~mm} \mathrm{Hg}$; and group III: mechanically ventilated to $\mathrm{PaCO}_{2}$ of $35-45 \mathrm{~mm}$ $\mathrm{Hg}$, tidal volume $10-14 \mathrm{ml} / \mathrm{kg}$. Group IV lambs were allowed to breathe spontaneously without assisted ventilation.

Ventilated groups. After premedication with intramuscular ketamine $10 \mathrm{mg} / \mathrm{kg}$ and acepromazine $0.1 \mathrm{mg} / \mathrm{kg}$, lambs in groups I-III had a $5.0 \mathrm{Fr}$ catheter placed in the distal aorta via the femoral artery using supplemental local anesthesia. This catheter was used for continuous blood pressure and heart rate monitoring and blood gas and $\mathrm{pH}$ determinations before the 
onset of and during ventilation. Under local lidocaine anesthesia, the trachea was then exposed and a $5.0 \mathrm{~mm}$ internal diameter cuffed endotracheal tube was secured by tracheostomy. Pancuronium bromide $0.1 \mathrm{mg} / \mathrm{kg}$ was then administered intravenously to paralyze the animal. The lambs were subsequently ventilated with $100 \%$ humidified and warmed oxygen with Sechrist pressure limited ventilators (Sechrist Industries, Anaheim, CA), using initial settings of: flow, $15 \mathrm{liter} / \mathrm{min}$; peak inspiratory pressure, $10 \mathrm{~cm} \mathrm{H}_{2} \mathrm{O}$; positive end expiratory pressure, $1 \mathrm{~cm} \mathrm{H}_{2} \mathrm{O}$; rate, 20 breaths/min; and inspiratory time, $0.7 \mathrm{~s}$. A baseline arterial blood gas and $\mathrm{pH}$ were measured on these settings. A Rashkind balloon catheter was then introduced into a femoral vein and advanced with fluoroscopy guidance to the right atrium and then across the patent foramen ovale to the left atrium. The balloon was inflated in the left atrium and pulled across the foramen ovale to the right atrium, creating an atrial septal defect. The Rashkind catheter was then withdrawn from the femoral vein, and a 5.0 Fr catheter was inserted in its place and threaded 7-8 $\mathrm{cm}$ into the vessel.

To generate a right to left shunt at the atrial level, a catheter with a distensible distal balloon was threaded to the right atrium via the right external jugular vein in a manner similar to that described by Fahey and Lister (14). Balloon position was confirmed by fluoroscopy. The shunt was demonstrated clinically by inflating the balloon with $2-3 \mathrm{ml}$ of contrast medium and documenting a substantial decrease in arterial $\mathrm{PO}_{2}$ from $>300$ $\mathrm{mm} \mathrm{Hg}$ to $35-50 \mathrm{~mm} \mathrm{Hg}$ in groups I, II, and III. The balloon was deflated in group III after the initial demonstration that a shunt could be created.

Each lamb then received ${ }^{32} \mathrm{P}$-labeled natural rabbit surfactant (approximately $5 \mathrm{mg}$ total lipid suspended in $10 \mathrm{ml} 0.9 \% \mathrm{NaCl}$ ) intratracheally to label the alveolar pools. The time between initial placement on the ventilator and administration of ${ }^{32} \mathrm{P}$ natural surfactant averaged $48 \pm 7 \mathrm{~min}$. The lambs were rotated to four different positions during the intratracheal injection to try to distribute the surfactant suspension uniformly. After the tracheal injection, the ventilator rate was increased to 30 breaths/ min, and peak inspiratory pressure increased to maintain ventilation. Only peak inspiratory pressure was subsequently changed to achieve the ventilatory goals for the animals in the different groups. The low rate, high tidal volume, low positive end expiratory pressure combination was selected for hyperventilation to avoid gas trapping. Group II lambs had $\mathrm{CO}_{2}$ added to the inspired gases at the onset of hyperventilation to maintain $\mathrm{PaCO}_{2}$ at 35$45 \mathrm{~mm} \mathrm{Hg}$.

A continuous infusion of $5 \%$ dextrose in $0.45 \% \mathrm{NaCl}$ was given to each lamb at $100 \mathrm{ml} / \mathrm{kg} / 24 \mathrm{~h}$. Body temperature was monitored with a rectal probe during the study. The lambs were kept paralyzed with $0.1 \mathrm{mg} / \mathrm{kg}$ pancuronium bromide given intravenously every $4 \mathrm{~h}$, and anesthesia was maintained with 10 $\mathrm{mg} / \mathrm{kg}$ ketamine and $0.1 \mathrm{mg} / \mathrm{kg}$ acepromazine given by intramuscular injection every $4 \mathrm{~h}$. Tidal volumes were measured hourly with a Fleisch pneumotachometer, and compliances were calculated as $\mathrm{ml}$ tidal vol $/ \mathrm{kg}$ body weight divided by the difference between the peak inspiratory pressure and the positive end expiratory pressure (15).

Unventilated group. After premedication with the same dose of intramuscular ketamine and acepromazine as for the previous animals, the group IV lambs were intubated orally with a 4.5$\mathrm{mm}$ internal diameter cuffed endotracheal tube, and the ${ }^{32} \mathrm{P}$ natural surfactant was given intratracheally. The lambs were then ventilated using $100 \%$ humidified and warmed oxygen with a flow of 15 liters/min; peak inspiratory pressure, $20 \mathrm{~cm} \mathrm{H}_{2} \mathrm{O}$; positive end expiratory pressure, $1 \mathrm{~cm} \mathrm{H}_{2} \mathrm{O}$; rate, 20 breaths/ min for 5-10 min to distribute the surfactant in the airways. During this brief period of ventilation, a $3.5 \mathrm{Fr}$ catheter was secured in a saphenous vein for subsequent vascular injections. The animals were extubated and returned to pens with their mothers for the duration of the experiment. They were subsequently disturbed for two brief periods $(<5 \mathrm{~min})$ to inject radiolabeled precursors before the animals were killed. A blood sample for venous blood gas and $\mathrm{pH}$ measurements was obtained from the saphenous catheter just before the animals were killed.

Preparation of radioactive natural surfactant. Radioactive large aggregate natural rabbit surfactant was isolated as previously described by centrifugation of alveolar washes from lungs of 3day-old rabbits that were each given $1 \mathrm{mCi}$ of $\left[{ }^{32} \mathrm{P}\right]$ orthophosphate by tracheal injection $24 \mathrm{~h}$ before the animals were killed (16). This radiolabeled surfactant was then suspended in $0.9 \%$ $\mathrm{NaCl}$ with unlabeled natural sheep surfactant to a concentration of approximately $5 \mathrm{mg}$ total surfactant lipid and $2 \mu \mathrm{Ci}{ }^{32} \mathrm{P}$ radioactivity $/ 10 \mathrm{ml}$. Although the labeled tracer surfactant was from rabbits rather than sheep, we found few differences in rates of clearance or tissue association patterns for species heterogenous surfactants (17).

Radioactive label administration. All lambs received two different radiolabeled precursors of surfactant phosphatidylcholine intravenously at different times as well as the intratracheal labeled surfactant. Surfactant pools in all animals were labeled with $\left[{ }^{3} \mathrm{H}\right]$ palmitic acid $(0.67 \mathrm{mCi} / \mathrm{kg})$ given by intravascular injection about $22 \mathrm{~h}$ before the animals were killed, primarily to study surfactant secretion. At $1 \mathrm{~h}$ before the animals were killed, $\left[{ }^{14} \mathrm{C}\right]$ palmitic acid $(25 \mu \mathrm{Ci} / \mathrm{kg})$ was given by intravascular injection to evaluate precursor incorporation into newly synthesized saturated phosphatidylcholine. Protein leak into the lungs was studied using [ $\left.{ }^{125} \mathrm{I}\right]$ albumin given by intravascular injection $2 \mathrm{~h}$ before death. $\left[{ }^{131}\right.$ I] albumin was given by intravascular injection 2 min before the animals were killed to estimate the blood volume retained within the lung tissue (15). Preparation of iodinated albumin using monomer standard bovine albumin and chloramine $\mathrm{T}$ was as previously described (15). Trichloroacetic acid precipitation of the iodinated albumin product yielded $>$ $97 \%$ trichloroacetic acid-precipitable radiolabeled protein complex.

Cardiac outputs, left to right ductal shunts, and atrial right to left shunts were measured in the mechanically ventilated lambs about $3 \mathrm{~h}$ before the animals were killed using radiolabeled 15 $\mu \mathrm{m}$ diameter microspheres. ${ }^{57} \mathrm{Co}$ microspheres were injected over $30 \mathrm{~s}$ into a $5.0 \mathrm{Fr}$ catheter inserted into the left ventricle via a right carotid artery cutdown while a reference sample was simultaneously being drawn from the aortic catheter into a heparinized glass syringe at a rate of $6 \mathrm{ml} / \mathrm{min}$ for 2 min using a Harvard pump (18). The left ventricular catheter was then removed. ${ }^{46} \mathrm{Sc}$ microspheres mixed with $8 \mathrm{ml}$ maternal blood were divided into two 4-ml aliquots. One 4-ml aliquot was injected through the femoral vein catheter while the other 4-ml aliquot was simultaneously injected into the left external jugular vein. After the animals were killed, the lungs were removed, and the rest of the body was carbonized and counted for microsphere content. Aliquots of lung homogenate also were taken in triplicate for microsphere counts. Cardiac outputs were measured using the reference sample drawn from the aorta during the left ventricular injections and using total radioactivity as ${ }^{57}$ Co counts in the body plus the lungs and the reference sample (18). The percentage of recovery in the lungs of the ${ }^{57} \mathrm{Co}$ microspheres injected into the left ventricle was a measure of left to right ductal shunting. Atrial right to left shunts were determined using the following formula: $\left[1-\left({ }^{46} \mathrm{Sc}\right.\right.$ lungs $/{ }^{46} \mathrm{Sc}$ lungs + carcass $\left.)\right] \times$ $100 \%=\%$ right to left shunt. Microsphere-associated radioactivity was counted using a 5-channel counter because of the presence of ${ }^{125} \mathrm{I}$ and ${ }^{131} \mathrm{I}$. Appropriate isotope standards were used for computerized cross channel and background corrections.

Processing of lungs. The lambs were killed with intravenous pentobarbital followed by exsanguination $8 \mathrm{~h}$ after receiving the intratracheal natural surfactant labeled with ${ }^{32} \mathrm{P}$. Groups I-III lambs had their endotracheal tubes cross-clamped, whereas lambs in group IV had endotracheal tubes secured by tracheostomy and cross-clamped. The chest of each lamb was then rapidly opened to expose the heart, and blood for the determination of labeled iodine content was aspirated from the ventricle into a heparinized syringe. In the mechanically ventilated lambs, the position of the intraatrial balloon was confirmed. The lungs of 
all lambs were carefully removed from the chest, inspected, and weighed. The hearts and major vessels were examined.

Sufficient saline to distend the lungs fully was washed in and out of the lungs three times and recovered. This wash procedure was repeated with four more aliquots of saline, and the five alveolar washes were pooled and the volume recorded (19). The lungs were then weighed, minced with scissors, and degassed in a vacuum chamber. On average, $7 \%$ of the saline volume was retained in the lung tissue, and this amount was similar in the four groups, supporting the consistency of the alveolar wash procedure. The tissue was then gently homogenized with an Ultra-Turrax homogenizer (Tekmar Co., Cincinnati, OH) in $350-450 \mathrm{ml} 0.25 \mathrm{M}$ sucrose/Tris buffer at $\mathrm{pH} 7.4$ (20). The final volume of the homogenized lung tissue was recorded. Duplicate aliquots from each lung homogenate were processed for lamellar bodies and microsomes using sucrose step gradients (20). The lamellar bodies and microsomes resuspended in saline as well as aliquots of alveolar washes and lung homogenates in triplicate were extracted with chloroform/methanol (21). Saturated phosphatidylcholine was recovered by column chromatography after osmium tetroxide oxidation (22). Phosphorous content was measured on an aliquot of the saturated phosphatidylcholine solution according to Bartlett (23); the remainder was used to measure radioactivity in Aquasol scintillation fluid (New England Nuclear, Boston, MA). Specific activities of ${ }^{3} \mathrm{H}$ and ${ }^{14} \mathrm{C}$ were determined for each sample as $\mathrm{cpm} / \mu \mathrm{mol}$ saturated phosphatidylcholine. Recovery of ${ }^{32} \mathrm{P}$-saturated phosphatidylcholine was determined in extracted alveolar washes and lung homogenates and expressed as a percentage of the total amount given to the lambs. Saturated phosphatidylcholine pool sizes were calculated for alveolar washes and lung homogenates of each animal and expressed as $\mu \mathrm{mol}$ saturated phosphatidylcholine $/ \mathrm{kg}$ body weight.

Radiolabeled albumin associated with alveolar washes, lung tissue and blood were measured. The ${ }^{131}$ I radioactivity associated with the lung homogenate was assumed to be from intravascular blood and was used to estimate the amount of blood retained in the lung tissue (15). The blood-associated ${ }^{125}$ I radioactivity was then subtracted from that measured for each lung. The remaining lung-associated ${ }^{125} \mathrm{I}$ radioactivity was expressed as a percentage of total injected dose. Protein in alveolar wash was measured according to Lowry (24) using a BSA standard.

Data analysis. Data are expressed as means \pm SEM. Statistical comparisons were performed by ANOVA followed by the Student Newman-Keuls multiple comparison procedure. Differences between groups were considered significant at $p<0.05$.

\section{RESULTS}

Description of animals. The four groups of lambs had similar ages, body weight, and sex distributions (Table 1). The mean heart rate in group I lambs (hyperventilated) was slightly higher than those of the other two mechanically ventilated groups (II, hyperventilated with added $\mathrm{CO}_{2}$ and III, ventilated with the lower tidal volumes); however, cardiac outputs and mean blood pressures were similar in the three groups. Atrial right to left shunt was measured at $5 \pm 1 \mathrm{~h}$ after onset of ventilation. Shunt values, obtained by calculation of the fraction of injected ${ }^{46} \mathrm{Sc}$ microsphere counts found in the carcass, were plotted on a semilog scale against the corresponding $\mathrm{PaO}_{2}$ at the time of injection, and a linear regression curve was generated $(r=0.98)$. Average shunt during the 8 -h study period was calculated from the mean $\mathrm{PaO}_{2}$ values in each group using this curve (Table 1). The hyperventilated groups (I and II) of lambs had similar shunts that were significantly different from the lambs ventilated at the lower tidal volumes (group III, $p<0.01$ ). Recovery of microspheres injected into the left ventricle from the lungs of the three groups of ventilated lambs was similar at 4 to $6 \%$. This low value indicated no significant left to right shunt at the level of the ductus arteriosus.

Tidal volumes were about $28 \mathrm{ml} / \mathrm{kg}$ and similar in the hyperventilated groups, whereas group III lambs were ventilated with significantly lower mean tidal volumes of $13 \mathrm{ml} / \mathrm{kg}$ (Fig. $1 A$ ). The tidal volumes in groups I and II were achieved with mean peak inspiratory pressures of $23 \mathrm{~cm} \mathrm{H}_{2} \mathrm{O}$, whereas $16 \mathrm{~cm} \mathrm{H} \mathrm{H}_{2} \mathrm{O}$ peak inspiratory pressure was used to support the group III lambs. Lung compliances, which were normal in all lambs at the onset of ventilation, increased after the onset of hyperventilation in groups I and II and persisted at those increased levels with time, whereas lung compliances in group III remained unchanged throughout the experiment (Fig. $1 B$ ). Arterial $\mathrm{PCO}_{2}$ values were successfully normalized to an average value of $38 \mathrm{~mm} \mathrm{Hg}$ in group II with additional inspired $\mathrm{CO}_{2}$, and this was similar to the mean value of $40 \mathrm{~mm} \mathrm{Hg}$ for group III, but significantly higher than the mean value of $18.7 \mathrm{~mm} \mathrm{Hg}$ for group I $(p<$ 0.01 , Fig. $1 C$ ). Mean $\mathrm{PaO}_{2}$ values in group III lambs were 330 $\mathrm{mm} \mathrm{Hg}$ and different from groups I and II, which had comparable low mean $\mathrm{PaO}_{2}$ values of about $42 \mathrm{~mm} \mathrm{Hg}(p<0.01$, Fig. $1 D)$. The $\mathrm{pH}$ values reflected the $\mathrm{PCO}_{2}$ values in the different groups of lambs (Table 1). Venous $\mathrm{PCO}_{2}$ and $\mathrm{pH}$ in group IV lambs measured just before the animals were killed indicated normal gas exchange.

Surfactant measurements. Surfactant pool sizes in both the alveolar and tissue compartments, estimated by saturated phosphatidylcholine content, were comparable in all groups (Table 2 ). Intratracheal administration of trace amounts of ${ }^{32} \mathrm{P}$ natural surfactant permitted us to label alveolar surfactant pools without significantly altering the sizes of the existing pools. Significantly less of the saturated phosphatidylcholine from the ${ }^{32} \mathrm{P}$ natural surfactant was recovered by alveolar wash from the two mechanically hyperventilated groups as compared to the lambs mechanically ventilated at the lower tidal volumes and the spontaneously breathing controls that had similar values, indicating a higher extent of tissue association with the increased ventilation (Fig. 2 ). Recovery of label in the total lung (the sum of the alveolar

Table 1. Characteristics of lambs studied*

\begin{tabular}{|c|c|c|c|c|c|}
\hline & $\begin{array}{c}\text { Group I: } \\
\text { hyperventilated } \\
\text { without added } \\
\mathrm{CO}_{2}\end{array}$ & $\begin{array}{c}\text { Group II: } \\
\text { hyperventilated } \\
\text { with added } \\
\mathrm{CO}_{2} \\
\end{array}$ & $\begin{array}{l}\text { Group III: } \\
\text { ventilated to } \\
\text { normal } \mathrm{CO}_{2}\end{array}$ & $\begin{array}{c}\text { Group IV: } \\
\text { spontaneously } \\
\text { breathing }\end{array}$ & $p<0.05$ \\
\hline No. of animals & 5 & 5 & 5 & 5 & \\
\hline Age (days) & $6.4 \pm 0.4$ & $4.8 \pm 0.5$ & $5.4 \pm 0.8$ & $4.4 \pm 0.2$ & \\
\hline Body wt (kg) & $3.6 \pm 0.1$ & $3.2 \pm 0.2$ & $3.3 \pm 0.3$ & $3.5 \pm 0.3$ & \\
\hline Male:female & $1: 4$ & $3: 2$ & $4: 1$ & $1: 4$ & \\
\hline Heart rate (beats/min) & $246 \pm 6$ & $228 \pm 6$ & $218 \pm 6$ & & II, III $<$ I \\
\hline $\begin{array}{l}\text { Mean arterial blood pressure } \\
(\mathrm{mm} \mathrm{Hg})\end{array}$ & $81 \pm 1$ & $84 \pm 4$ & $86 \pm 3$ & & \\
\hline Cardiac output $(\mathrm{ml} / \mathrm{kg} / \mathrm{min})$ & $221 \pm 45$ & $282 \pm 10$ & $274 \pm 14$ & & \\
\hline$\%$ right to left shunt & $56.5 \pm 1.4$ & $57.9 \pm 1.3$ & $4.7 \pm 1.3$ & & III $<$ I, II \\
\hline Mean pH when killed & $7.43 \pm 0.01$ & $7.34 \pm 0.02$ & $7.37 \pm 0.01$ & $7.38 \pm 0.01$ & II, III, IV $<$ I \\
\hline
\end{tabular}

$*$ Values are given as means \pm SEM. 

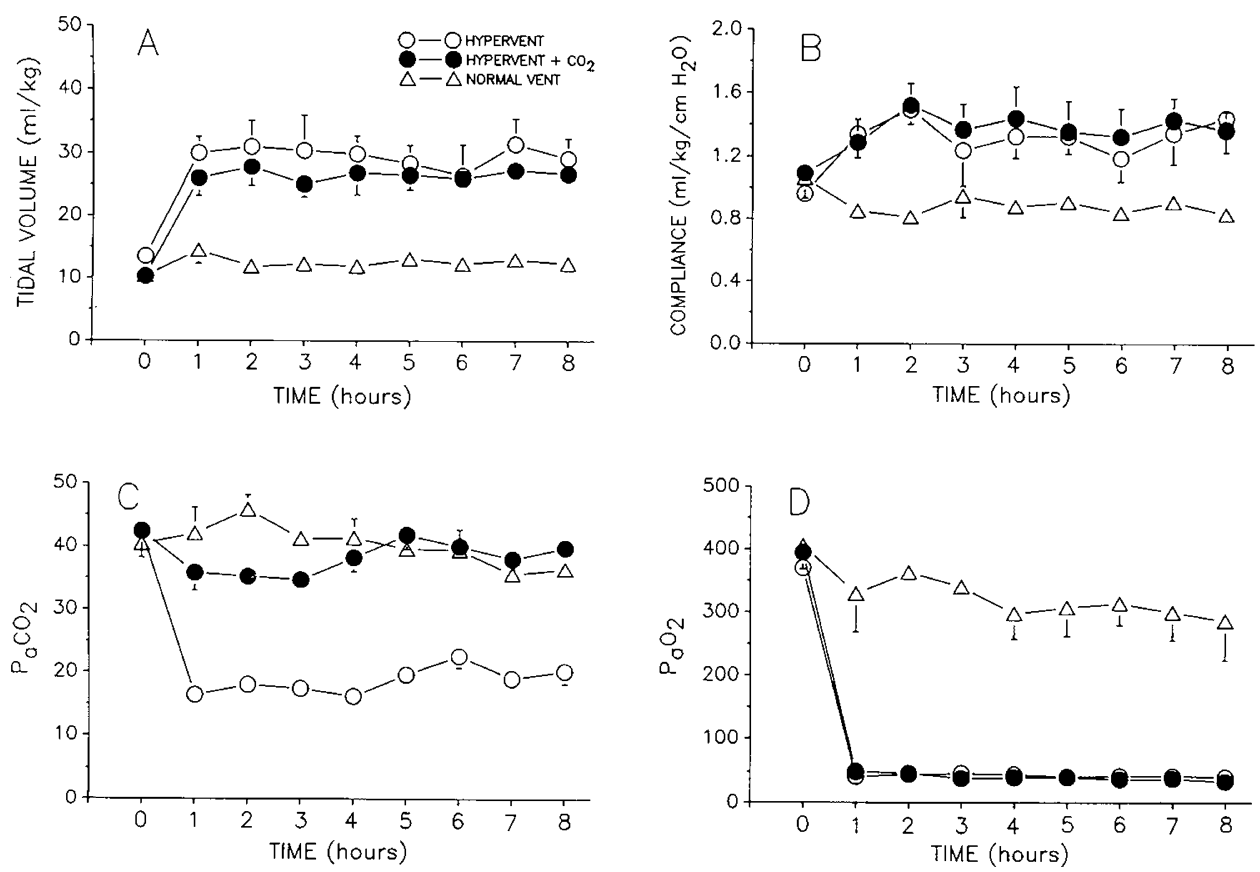

Fig. 1. Comparison of mechanically ventilated lambs from onset of mechanical ventilation to time animals were killed. Symbols for each group of lambs are identified on the figure. Time 0 represents measurements just before administration of intratracheal tracer surfactant labeled with ${ }^{32} \mathrm{P}$ Values are means \pm SEM. Representative error bars not shown fall within the data point.

Table 2. Measurements of surfactant phosphatidylcholine*

\begin{tabular}{|c|c|c|c|c|c|}
\hline & $\begin{array}{c}\text { Group I: } \\
\text { hyperventilated } \\
\text { without added } \\
\mathrm{CO}_{2} \\
\end{array}$ & $\begin{array}{c}\text { Group II: } \\
\text { hyperventilated } \\
\text { with added } \\
\mathrm{CO}_{2} \\
\end{array}$ & $\begin{array}{l}\text { Group III: } \\
\text { ventilated to } \\
\text { normal } \mathrm{CO}_{2} \\
\end{array}$ & $\begin{array}{l}\text { Group IV: } \\
\text { spontaneously } \\
\text { breathing }\end{array}$ & $p<0.05$ \\
\hline \multicolumn{6}{|l|}{$\begin{array}{l}\text { Saturated phosphatidyl- } \\
\text { choline pool size } \\
(\mu \mathrm{mol} / \mathrm{kg})\end{array}$} \\
\hline $\mathrm{AW}$ & $122 \pm 14$ & $120 \pm 15$ & $144 \pm 12$ & $137 \pm 15$ & \\
\hline $\mathrm{AW}+\mathrm{L}$ & $249 \pm 24$ & $258 \pm 28$ & $255 \pm 14$ & $247 \pm 16$ & \\
\hline $\begin{array}{l}\text { Ratio of }{ }^{32} \mathrm{P} \text { specific activ- } \\
\text { ity microsome/lamel- } \\
\text { lar bodies }\end{array}$ & $0.27 \pm 0.04$ & $0.33 \pm 0.06$ & $0.31 \pm 0.09$ & $0.60 \pm 0.06$ & I, II, III $<$ IV \\
\hline \multicolumn{6}{|l|}{${ }^{3} \mathrm{H}$ specific activity } \\
\hline AW & $7585 \pm 961$ & $11763 \pm 492$ & $12779 \pm 2245$ & $11159 \pm 1184$ & \\
\hline $\mathrm{L}$ & $19264 \pm 2932$ & $21528 \pm 2583$ & $29153 \pm 5230$ & $32027 \pm 3743$ & \\
\hline LB & $20426 \pm 2744$ & $23910 \pm 3381$ & $28144 \pm 6764$ & $18391 \pm 1521$ & \\
\hline M & $22677 \pm 2394$ & $22881 \pm 1428$ & $30327 \pm 4521$ & $26430 \pm 3893$ & \\
\hline$\%{ }^{3} \mathrm{H}$ label in $\mathrm{AW}$ & $27.7 \pm 2.1$ & $32.9 \pm 2.9$ & $37.8 \pm 3.4$ & $28.3 \pm 2.5$ & \\
\hline \multicolumn{6}{|l|}{${ }^{14} \mathrm{C}$ specific activity } \\
\hline $\mathrm{L}$ & $1260 \pm 307$ & $1115 \pm 524$ & $2073 \pm 427$ & $2152 \pm 249$ & \\
\hline M & $2229 \pm 599$ & $2285 \pm 890$ & $3288 \pm 816$ & $2518 \pm 489$ & \\
\hline
\end{tabular}

* Values are given as means \pm SEM. Abbreviations: $\mathrm{AW}=$ alveolar wash; $\mathrm{L}=$ lung homogenate after alveolar wash; $\mathrm{LB}=$ lamellar body fraction; $\mathrm{M}=$ microsome fraction. Specific activity denotes $\mathrm{cpm} / \mu \mathrm{mol}$ saturated phosphatidylcholine.

wash plus lung homogenate) was similar in groups II, III, and IV but was decreased in group I when compared to group IV only. The ratio of ${ }^{32} \mathrm{P}$ specific activities in the microsomes compared to the lamellar bodies was significantly lower in the mechanically ventilated groups as compared to the spontaneously breathing groups of lambs, suggesting that more of the labeled tracer surfactant was maintained in the resecretion pathway with ventilation (Table 2).

The specific activities of $\left[{ }^{3} \mathrm{H}\right]$ palmitic acid-labeled saturated phosphatidylcholine in the lamellar body, microsome, lung tissue and alveolar compartments were comparable for the four groups $22 \mathrm{~h}$ after the labeled precursor was given. About $30 \%$ of the total lung $\left[{ }^{3} \mathrm{H}\right]$ palmitic acid-labeled saturated phosphatidylcho- line was recovered by alveolar wash in all groups. Specific activities of the $\left[{ }^{14} \mathrm{C}\right]$ palmitic acid-labeled saturated phosphatidylcholine in the various fractions were not significantly different between the groups of animals. Very little $\left[{ }^{14} \mathrm{C}\right]$ pamitic acidlabeled saturated phosphatidylcholine was recovered in the alveolar washes or lamellar bodies. This indicates that synthesis, but not storage and secretion, had occurred within the hour between isotope injection and the time the animals were killed.

Protein leak measurements. No differences in protein leak, measured by recovery of intravascularly administered $\left[{ }^{125} \mathrm{I}\right] \mathrm{al}-$ bumin from the airspaces and lung tissue, were found between the groups (Table 3). Similarly, total protein content in the alveolar wash was not different in the four groups. 


\section{DISCUSSION}

Effects of hyperventilation on cardiac outputs, organ blood flows, and cellular metabolism have been reported in newborn animal models (25), but there are no studies of effects of mechanical hyperventilation on the surfactant system in the newborn. Similarly, effects of mechanical ventilation on the surfactant system of the newborn are not well described. We developed a newborn lamb model where mechanical hyperventilation was performed after creation of an atrial right to left shunt. The shunt was created to better mimic the clinical situation of decreased pulmonary blood flow and low systemic $\mathrm{PaO}_{2}$ values that is managed clinically with hyperventilation. We recognize that these animals do not have the associated problems of pulmonary hypertension and any underlying lung disease. However, the model has the advantages that a thoracotomy was not required, and the magnitude of the atrial shunt could easily be adjusted by changing the volume of the atrial balloon. We did not see a fall in left ventricular output, the predictable result of balloon inflation in the right atrium in the absence of an atrial septal defect (14). The animals were quite stable for the 8-h study period. This model should be useful to others who want to change arterial $\mathrm{PO}_{2}$ values without changing alveolar $\mathrm{PO}_{2}$ values or cardiac output.

Previous studies reported effects of hyperventilation on lung function using adult animal lung models. Decreased compliance after periods up to $4 \mathrm{~h}$ of increased ventilation were attributed to altered surfactant function because extracts from these lungs exhibited increased minimal surface tensions (6-10). Increased alveolar surfactant phospholipids were found by Oyarzun and Clements $(8,9)$ after hyperventilation of adult rabbits for periods up to $4 \mathrm{~h}$. They postulated that increased secretion of tissue pools occurred followed by inactivation. High peak inspiratory pressure hyperventilation of adult sheep for periods up to $48 \mathrm{~h}$ similarly resulted in development of decreased lung compliance, acute respiratory failure, and increased alveolar wash fluid minimal

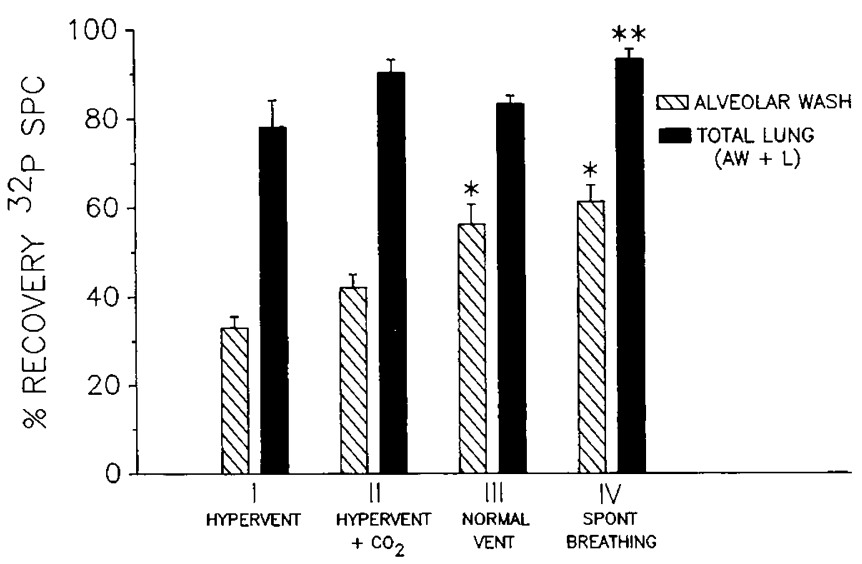

Fig. 2. Percentage of recovery of ${ }^{32} \mathrm{P}$-labeled saturated phosphatidylcholine in alveolar wash $(A W)$ and total lung $(A W+L=\mathrm{AW}+$ lung homogenate after alveolar wash). Values are shown as means \pm SEM. ${ }^{*} p$ $<0.05$ I, II $<$ III, IV; ${ }^{* *} p<0.05$ I $<$ IV. surface tension values as early as 6 to $12 \mathrm{~h}$ after onset of hyperventilation (26). Morphometric analysis of adult dog lungs hyperventilated for $4 \mathrm{~h}$ in the presence of relative hypoperfusion induced by pulmonary artery occlusion documented decreased lamellar body volume densities in type II cells, an effect that was moderated by the addition of $\mathrm{CO}_{2}$ to the inspired gases (11). In subsequent studies using excised adult dog lungs subjected to high tidal volume ventilation with and without varying amounts of added $\mathrm{CO}_{2}$, alveolar hypocapnia rather than the level of ventilation appeared to be the primary mediator of lamellar body depletion in type II cells (12).

Alveolar wash-saturated phosphatidylcholine pool sizes were not different in the four groups that we studied. The alveolar pool sizes were very large in these approximately 1-wk-old lambs. For comparison, adult rabbits, rats, and sheep would have pool sizes of saturated phosphatidylcholine of about 4 to $10 \mu \mathrm{mol} / \mathrm{kg}$ body weight, while 1-wk-old rabbits have alveolar pool sizes of about $40 \mu \mathrm{mol} / \mathrm{kg}$ body weight (13). The alveolar surfactantsaturated phosphatidylcholine pool was about $50 \%$ of the total lung surfactant-saturated phosphatidylcholine, a value very much higher than the approximately $15 \%$ of total lung surfactant-saturated phosphatidylcholine found in alveolar washes of adult rats and rabbits (27). Mechanical ventilation at the lower tidal volumes did not change alveolar wash-saturated phosphatidylcholine pool sizes or total lung-saturated phosphatidylcholine as compared to spontaneously breathing controls. Ennema et al. (4) similarly found no differences in the alveolar wash saturated phosphatidylcholine pool sizes in mechanically ventilated and spontaneously breathing adult rabbits. However, in contrast to what others have reported in adult animals (8-10), we found no increase in alveolar surfactant pool size after mechanical hyperventilation of these term newborn lambs. It is conceivable that so much of the available lung-saturated phosphatidylcholine was already in the alveoli that stimulated secretion either did not occur or was not detectable. Perhaps mean $\mathrm{PCO}_{2}$ values of about $20 \mathrm{~mm} \mathrm{Hg}$ and/or the increased tidal volumes were not sufficient to increase surfactant secretion. That the spontaneously breathing control lambs had similarly large alveolar surfactant pool sizes suggested that the secretory mechanisms in these 1-wk-old lambs were functioning at much higher levels than previously reported in adult or preterm animals (2729).

Using two radiolabeled precursors administered at specified times, we tried to probe surfactant synthesis and secretion. In support of lack of a large effect of mechanical ventilation on surfactant secretion was the equivalent recovery in all groups of the $\left[{ }^{3} \mathrm{H}\right]$ palmitic acid-labeled saturated phosphatidylcholine in the tissue and alveolar pools $22 \mathrm{~h}$ after isotope injection. Peak alveolar recovery of labeled saturated phosphatidylcholine was shown to occur about $40 \mathrm{~h}$ after precursor injection in newborn lambs (20). Therefore, we anticipated that if increased secretion occurred, we would see increased amounts of labeled saturated phosphatidylcholine in the alveolar wash. However, all four groups of animals had secreted about $30 \%$ of the total lung $\left[{ }^{3} \mathrm{H}\right]$ palmitic acid labeled saturated phosphatidylcholine by $22 \mathrm{~h}$, indicating that these somewhat older lambs had already secreted a higher percentage of labeled saturated phosphatidylcholine than

Table 3. Measurements of protein leak*

\begin{tabular}{|c|c|c|c|c|c|}
\hline & $\begin{array}{c}\text { Group I: } \\
\text { hyperventilated } \\
\text { without added } \\
\mathrm{CO}_{2}\end{array}$ & $\begin{array}{c}\text { Group II: } \\
\text { hyperventilated } \\
\text { with added } \\
\mathrm{CO}_{2}\end{array}$ & $\begin{array}{l}\text { Group III: } \\
\text { ventilated to } \\
\text { normal } \mathrm{CO}_{2} \\
\end{array}$ & $\begin{array}{c}\text { Group IV: } \\
\text { spontaneously } \\
\text { breathing }\end{array}$ & $p<0.05$ \\
\hline \multicolumn{6}{|c|}{$\%$ recovery of ${ }^{125} \mathrm{I}$-albumin } \\
\hline AW & $0.56 \pm 0.11$ & $0.50 \pm 0.07$ & $0.54 \pm 0.07$ & $0.56 \pm 0.08$ & NS \\
\hline $\mathrm{L}$ & $0.98 \pm 0.18$ & $0.86 \pm 0.14$ & $0.82 \pm 0.09$ & $0.53 \pm 0.08$ & NS \\
\hline AW protein $(\mathrm{mg} / \mathrm{kg})$ & $104 \pm 17$ & $93 \pm 11$ & $97 \pm 3$ & $100 \pm 17$ & NS \\
\hline
\end{tabular}

* Values are expressed as means \pm SEM. Abbreviations: $\mathrm{AW}=$ alveolar wash; $\mathrm{L}=$ lung homogenate after alveolar wash; NS $=$ no significant difference. 
would be anticipated for either newborn or adult animals (29). However, lamellar body specific activities were about twice the specific activities in the alveolar washes, suggesting that more labeled saturated phosphatidylcholine was available for secretion (29). Mechanical hyperventilation did not alter lamellar body to alveolar wash specific activity ratios which should be relatively sensitive indicators of surfactant metabolism.

The $\left[{ }^{14} \mathrm{C}\right]$ palmitic acid was given $1 \mathrm{~h}$ before sacrifice to see if the amount of incorporation into saturated phosphatidylcholine would change. Palmitate incorporation into lung-saturated phosphatidylcholine previously was found to be very rapid and should be completed in less than $1 \mathrm{~h}$ with no secretion of labeled saturated phosphatidylcholine (20). A decrease in incorporation would be consistent with decreased synthesis, assuming that palmitate precursor pools did not change. Because no significant change occurred with the mechanical hyperventilation, we assume as a first approximation that there was no effect on synthesis. However, the values for the hyperventilated groups tended to be lower, and values for isotope incorporation following bolus intravascular injection in whole animals vary considerably, making the conclusion that synthesis was not affected quite tentative.

Intratracheal administration of trace amounts of ${ }^{32} \mathrm{P}$ natural surfactant allowed us to label the alveolar surfactant pools in these lambs. More of the ${ }^{32} \mathrm{P}$ surfactant was lung tissue associated in the hyperventilated groups compared to the other two groups. Added $\mathrm{CO}_{2}$ had no modifying effect on these findings. In general, there was more variability in label recovery in lambs mechanically hyperventilated without added $\mathrm{CO}_{2}$. This may have been a factor in the small but apparently significantly increased total lung clearance of saturated phosphatidylcholine in these lambs compared to the spontaneously breathing group. The increased tissue association could be either a nonspecific phenomenon or an indication of increased recycling (13). In support of the latter was the increased ${ }^{32} \mathrm{P}$ specific activity in lamellar bodies relative to the microsomes in the ventilated groups compared to the unventilated group. Assuming that the exogenously administered labeled surfactant followed the same pathways as the existing alveolar surfactant pools in these lambs, it is possible that increased secretion of tissue surfactant pools occurred but was masked both by very large alveolar pools and rapid recycling into the tissue compartment because intraalveolar surfactant pools were similar in all groups.

Lung injury is known to occur with prolonged hyperoxia and mechanical ventilation. Hyperoxia causes pulmonary edema and atelectasis (2), neither of which were apparent in these lambs. Artificial ventilation of surfactant-deficient lungs has been shown to increase protein leak, with the magnitude of leak increasing with increased peak inspiratory pressure used to ventilate the lung and with decreasing gestational age (15). In contrast, the lungs of mature lambs with adequate surfactant pools show little protein leak despite hyperventilation and higher peak inspiratory pressures (15). The lambs in this study had minimal protein leaks that were similar for all groups. Although no microscopic studies were performed, no significant ventilator or oxygeninduced lung injury was detected in these lambs, as indicated by the absence of increased protein leaks, gross atelectasis or hemorrhage, and unaltered compliances during the course of the study.

In summary, these experiments showed no large effects of mechanical ventilation, even at very high tidal volumes on the surfactant system, a result that was different from those reported in the literature, at least for hyperventilated adult animals. The use of a newborn model where larger surfactant pool sizes were present may account for the preservation of dynamic compliances in these lambs as compared with hyperventilated adult lung models. Although no surface tension measurements were performed, altered surfactant function was unlikely in view of compliance measurements which were normal and actually increased with hyperventilation during the course of the study. The longer period of hyperventilation than previously studied in experimental animals may additionally have allowed for a new equilibrium to be reached. Finally, the lack of an obvious effect on surfactant secretion may have been masked by an increased rate of recycling. More elaborate studies, perhaps with a greater emphasis on quantifying the recycling pathway, would be needed to detect any more subtle effects on surfactant metabolism.

\section{REFERENCES}

1. Duara S, Gewitz MH, Fox WH 1984 Use of mechanical ventilation for clinical management of persistent pulmonary hypertension of the newborn. Clin Perinatol 11:641-652

2. Hansen TN, Gest AL 1984 Oxygen toxicity and other ventilatory complications of treatment of infants with persistent pulmonary hypertension. Clin Perinatol 11:653-672

3. Berry D, Ikegami M, Jobe A 1986 Respiratory distress and surfactant inhibition following vagotomy in rabbits. J Appl Physiol 61:1741-1748

4. Ennema JJ, Reijngoud DJ, Wildevuur CHRH, Egberts J 1984 Effects of artificial ventilation on surfactant phospholipid metabolism in rabbits. Respir Physiol 58:15-28

5. Massaro D, Clerch L, Temple D, Baier H 1983 Surfactant deficiency in rats without a decreased amount of extracellular surfactant. J Clin Invest $71: 1536-1543$

6. McClenahan JB, Urtnowski A 1967 Effect of ventilation on surfactant and its turnover rate. J Appl Physiol 23:215-220

7. Faridy EE, Permutt S, Riley RL 1966 Effect of ventilation on surface forces in excised dog lungs. J Appl Physiol 21:1453-1462

8. Oyarzun MJ, Clements JA 1977 Ventilatory and cholinergic control of pulmonary surfactant in the rabbit. J Appl Physiol 43:39-45

9. Oyarzun MJ, Clements JA 1978 Control of lung surfactant by ventilation, adrenergic mediators and prostaglandins in the rabbit. Am Rev Respir Dis 117:879-891

10. Wyszogrodski I, Kyei-Aboagye K, Taeusch HW, Avery ME 1975 Surfactan inactivation by hyperventilation: conservation by end-expiratory pressure. $J$ Appl Physiol 38:461-466

11. Shepard JW, Hauer D, Miyai K, Moser KM 1980 Lamellar body depletion in dogs undergoing pulmonary artery occlusion. J Clin Invest 66:36-42

12. Shepard JW, Dolan GF, Yu SY 1982 Factors regulating lamellar body volume density of type II pneumocytes in excised dog lungs. J Appl Physiol 53:555562

13. Jobe AH, Jacobs HC 1984 Catabolism of pulmonary surfactant. In: Robertson B, Van Golde LMG, Batenburg JJ (eds) Pulmonary Surfactant. Elsevie Science Publishers, Amsterdam, pp 271-283

14. Fahey JT, Lister G 1985 A simple method for reducing cardiac output in the conscious lamb. J Appl Physiol 249:H188-H192

15. Jobe AH, Jacobs H, Ikegami M, Berry D 1985 Lung protein leaks in ventilated lambs: effect of gestational age. J Appl Physiol 58:1246-125!

16. Jacobs H, Jobe AH, Ikegami M, Jones S, Miller D 1983 Route of incorporation of alveolar palmitate and choline into surfactant phosphatidylcholine in rabbits. Biochim Biophys Acta 752:178-181

17. Pettenazzo A, Oguchi K, Seidner S, Ikegami M, Berry D, Jobe AH 1986 Clearance of natural surfactant phosphatidylcholine from 3-day-old rabbit lungs. Effects of dose and species. Pediatr Res 20:1139-1142

18. Heymann MA, Payne BD, Hoffman JIE, Rudolph AM 1977 Blood flow measurements with radionuclide labeled particles. Prog Cardiovas Dis 20:5579

19. Jobe AH, Ikegami M, Jacobs HC, Jones SJ 1983 Surfactant pool sizes and severity of respiratory distress syndrome in prematurely delivered lambs. Am Rev Respir Dis 127:751-755

20. Jobe AH, Ikegami M, Sarton-Miller I, Barajas L 1980 Surfactant metabolism of newborn lamb lungs studied in vivo. J Appl Physiol 49:1091-1098

21. Bligh EG, Dyer WJ 1959 A rapid method of total lipid extraction and purification. Can J Biochem Physiol 37:911-917

22. Mason RJ, Nellenbogen J, Clements JA 1976 Isolation of disaturated phosphatidylcholine with osmium tetroxide. J Lipid Res 17:281-284

23. Bartlett GR 1959 Phosphorous assay in column chromatography. J Biol Chem 234:466-468

24. Lowry OH, Rosebronger J, Farr AL, Randall RJ 1951 Protein measurement with the Folin phenol reagent. J Biol Chem 193:265-275

25. Reuter JH, Disney TA 1986 Regional cerebral blood flow and cerebral metabolic rate of oxygen during hyperventilation in the newborn dog. Pediatr Res 20:1102-1106

26. Kolobow T, Moretti MP, Fumagalli R, Mascheroni D, Prato P, Chen V, Joris M 1987 Severe impairment in lung function induced by high peak airway pressure during mechanical ventilation. Am Rev Respir Dis 135:312-315

27. Wright JR, Clements JA 1987 Metabolism and turnover of lung surfactant. Am Rev Respir Dis 136:426-444

28. Ikegami M, Jobe AH, Yamada T, Seidner SR, Priestley A, Ruffini L 1988 Surfactant metabolism in surfactant treated premature ventilated lambs. Pediatr Res 23:510A

29. Jacobs H, Jobe A, Ikegami M, Jones S 1982 Surfactant phosphatidylcholine source, fluxes, and turnover times in 3-day-old, 10-day-old, and adult rabbits. J Biol Chem 257:1805-1810 